\title{
STUDI INTEGRITAS TIANG DENGAN CROSSHOLE SONIC LOGGING, CROSSHOLE TOMOGRAPHY, PILE INTEGRITY TEST, DAN PARALLEL SEISMIC
}

\author{
Fanny Oktarina ${ }^{1}$, Sunarjo Leman ${ }^{2}$ dan Ali Iskandar ${ }^{3}$ \\ ${ }^{1}$ Program Studi Sarjana Teknik Sipil, Universitas Tarumanagara, Jl. Letjen S. Parman No.1 Jakarta \\ Email:fannyokt97@gmail.com \\ ${ }^{2}$ Program Studi Sarjana Teknik Sipil, Universitas Tarumanagara, Jl. Letjen S. Parman No.1 Jakarta \\ Email: sunarjo@ft.untar.ac.id \\ ${ }^{3}$ Program Studi Sarjana Teknik Sipil, Universitas Tarumanagara, Jl. Letjen S. Parman No.1 Jakarta \\ Email: ali.iskandar1999@gmail.com
}

\begin{abstract}
ABSTRAK
Fondasi merupakan unsur yang sangat penting dalam suatu bangunan. Suatu bangunan akan mengalami kegagalan struktur jika fondasi yang direncanakan tidak memenuhi persyaratan meskipun struktur atasnya telah direncanakan dengan baik. Kegagalan struktur yang dimaksud adalah bahan yang digunakan untuk menyalurkan beban bangunan harus cukup kuat dan tidak mengalami kerusakan bahan. Demi mencegah kegagalan struktur, dilakukan uji integritas pada tiang yang tidak merusak struktur fondasi. Uji integritas yang akan dilakukan adalah Crosshole Sonic Logging, Crosshole Tomography, Pile Integrity Test, dan Parallel Seismic. Dari hasil pengujian integritas pada tiang tersebut didapatkan kedalaman tiang dan letak kerusakan tiang.
\end{abstract}

Kata kunci: fondasi, integritas, kedalaman tiang, kerusakan tiang

\section{PENDAHULUAN}

\section{Latar Belakang}

Fondasi merupakan unsur yang sangat penting dalam suatu bangunan, baik itu gedung tinggi, bangunan industri maupun jembatan. Suatu bangunan akan mengalami kegagalan jika fondasi yang direncanakan tidak memenuhi persyaratan meskipun struktur atasnya telah direncanakan dengan baik, dikarenakan fondasi merupakan bagian dari struktur yang berfungsi meneruskan beban struktur atas ke lapisan tanah yang mempunyai daya dukung aman. Struktur fondasi dapat memikul bangunan dengan aman dengan syarat fondasi tidak boleh mengalami keruntuhan daya dukung maupun kegagalan struktur. Keruntuhan daya dukung dalam hal ini adalah fondasi tidak boleh mengalami penurunan yang dapat membahayakan struktur yang dipikulnya serta tanah yang terbebani tidak mengalami keruntuhan. Sedangkan kegagalan struktur yang dimaksud dalam hal ini adalah bahan yang digunakan untuk menyalurkan beban bangunan harus cukup kuat dan tidak mengalami kerusakan bahan. Hal ini dikenal dengan keruntuhan (integrity) bahan.

Pada sekitar tahun 80-an, para ahli berusaha mencari teknologi pengujuan pelaksanaan uji beban dan uji keruntuhan bahan pada fondasi yang ekonomis, praktis dan tidak merusak struktur fondasi. Kemudian diperkenalkan teknik uji keruntuhan tiang beton yang tidak merusak struktur tiang, yaitu teknik uji integritas tiang atau pile integrity testing (PIT) dan Crosshole Sonic Logging (CSL). Penggunaan metode Crosshole Sonic Logging (CSL) biasanya dipadukan dengan Crosshole Tomography (CT) untuk mendapatkan data kerusakan fondasi seperti ukuran dan bentuknya dalam 2 dimensi serta 3 dimensi. Lalu diperkenalkan metode untuk menentukan kedalaman fondasi untuk jembatan dan gedung yaitu parallel seismic (PS).

Pada umumnya ada dua tipe kasus yang tidak diketahui kondisi ekistingnya, yaitu:

1. Jenis dan kedalaman fondasi yang tidak diketahui.

2. Jenis pondasinya diketahui, tetapi kedalamannya tidak diketahui.

Pada penyusunan skripsi ini, penulis akan menganalisa kasus fondasi, dimana jenis fondasi diketahui, yaitu tiang tunggal, tetapi kedalamannya atau panjang tiang tidak diketahui. Untuk mengetahui kedalaman fondasi digunakan metode parallel seismic (PS).

Dalam proses analisa ini, dibutuhkan data-data yang diperoleh dari pengujian fondasi di lapangan dengan bantuan alat Crosshole Sonic Logging, Crosshole Tomography, Pile Integrity Test, dan Parallel Seismic. 


\section{Batasan masalah}

Dalam penelitian ini, batasan-batasan yang digunakan sebagai berkut:

1. Melakukan uji hanya untuk menganalisa 1 tiang.

2. Tiang yang diuji adalah tiang bor.

3. ASTM D-6760-08 Standard Test Method for Integrity Testing of Concrete Deep Foundation by Ultrasonic Crosshole Testing.

4. ASTM D-5882-07 Standard Test Method for Low Strain Impact Integrity Testing of Deep Foundations.

5. ACI 228.2R Report on Nondestructive Test Methods for Evaluation of Concrete in Structures.

\section{Rumusan masalah}

Rumusan masalah yang akan dibahas pada penelitian ini:

1. Profilling tiang menggunakan tes integritas.

2. Profilling tiang menggunakan Crosshole Sonic Logging test dan Crosshole Tomography.

3. Deteksi kedalaman fondasi menggunakan uji seismic.

\section{Tujuan penelitian}

Adapun beberapa tujuan dari penelitian ini adalah:

1. Untuk mengetahui integritas tiang.

2. Untuk mengetahui kondisi beton apakah mengalami pergumpalan atau tidak serta mengetahui letak kerusakan yang terjadi.

3. Untuk mengetahui kedalaman pondasi dengan menggunakan uji seismic.

\section{DASAR TEORI}

\section{Fondasi tiang Bor}

Fondasi tiang bor (bored pile) adalah fondasi tiang yang pemasangannya dilakukan dengan mengebor tanah pada awal pengerjaannya (Hardiyatmo, 2010). Tiang bor dipasang ke dalam tanah dengan cara mengebor tanah terlebih dahulu, baru kemudian diisi tulangan dan dicor beton. Tiang ini biasanya dipakai pada tanah yang stabil dan kaku, sehingga memungkinkan untuk membentuk lubang yang stabil dengan alat bor. Jika tanah mengandung air, pipa besi dibutuhkan untuk menahan dinding lubang dan pipa ini ditarik ke atas pada waktu pengecoran beton. Pada tanah yang keras atau batuan lunak, dasar tiang dapat dibesarkan untuk menambah tahanan dukung ujung tiang.

\section{Metode Crosshole Sonic Logging}

Crosshole Sonic Logging pertama kali dikembangkan oleh French National Construction Industry Center (CEBTP) di akhir tahun 1960-an. Metode ini sekarang banyak dipergunakan secara luas untuk menentukan integritas dari tiang bor (bored pile) atau sumuran bor (drilled shafts). Alat yang digunakan untuk memastikan kualitas dari bermacam-macam fondasi dan dinding penahan tanah yang terbuat dari material beton seperti pada Gambar 2.2 di bawah ini. Dalam pengujian tiang bor, Crosshole Sonic Logging digunakan untuk memastikan integritas dari beton, letak kerusakan dan untuk evaluasi efektifitas dari perbaikan.

\section{Metode Crosshole Tomography}

Crosshole Tomography test digunakan untuk menentukan ukuran, lokasi dan beberapa cacat yang umum ditemukan di lubang bor, seal footings dan cairan atau dinding penahan tanah (D-wall). Crosshole Tomography test menunjukkan rambatan dari gelombang ultrasonik di antara dua atau lebih pipa untuk mengukur kecepatan dan kekuatan sinyal dari rambatan gelombang tersebut. Tes ini dapat dilakukan pada pondasi beton yang menyediakan dua atau lebih pipa atau lobang bor yang telah disediakan yang dapat menampung air di fondasi tersebut. Crosshole Tomography test dapat digunakan untuk menggambarkan penyimpangan kritis di piers bawah air dan fondasi dengan mengikat pipa akses di sisi-sisi lubang bor tersebut. Crosshole Tomography test ini biasa digunakan ketika suatu cacat sudah di identifikasi dengan tes awal seperti Crosshole Sonic Logging dan membutuhkan analisis lebih lanjut. Tidak seperti Crosshole Sonic Logging test yang hanya menyajikan data horizontal, Crosshole Tomography test menyajikan data dari setiap sudut (secara vertikal dan horizontal), yang dimana menyajikan secara detail cacat yang dipertanyakan.

\section{Metode Pile Integrity Test}

Pile integrity test biasa dikenal juga sebagai pengujian dinamis regangan rendah (low strain dynamic testing) untuk memeriksa adanya potensi berbahaya pada fondasi tiang bor seperti adanya rongga atau retakan, integritas tiang pada 
kedalaman total, dan menentukan panjang tiang yang belum diketahui pada struktur yang ada. Ketika tiang pancang dipasang, kerusakan akan mungkin terjadi.

\section{Metode Parallel Seismic}

Parallel Seismic digunakan untuk menentukan kedalaman dan integritas dari fondasi ketika bagian atas tidak dapat diakses atau ketika tiang terlalu panjang dan ramping untuk di tes dengan teknik bergema, atau di bawah pile cap yang terkubur. Parallel Seismic test menyediakan informasi mengenai kedalaman dan mengenai kecepatan tekan dari fondasi dan dapat digunakan pada beton, kayu, batu dan fondasi baja. Parallel Seismic juga menyediakan informasi mengenai tanah di dasar fondasi. Yang harus diperhatikan dalam tes ini yaitu membutuhkan instalasi pipa dalam lubang bor yang sudah terisi air atau di grout. Parallel Seismic dapat diaplikasikan pada piers penyangga, fondasi dalam, dan sheet piles and footings.

\section{METODOLOGI PENELITIAN}

\section{Metode pengumpulan data}

Metode yang digunakan untuk pengumpulan data penelitian ini adalah teknik dokumentasi yaitu pengumpulan data dari tiang yang akan diuji. Pengumpulan data yang dilakukan berupa kedalaman tiang, diameter tiang, panjang stick up, jumlah pipa, dan jarak antar pipa.

\section{Metode pengujian}

Studi integritas tiang dilakukan dengan menguji tiang di lapangan dengan menggunakan metode Crosshole Sonic Logging, Crosshole Tomography, Pile Integrity Test, dan Parallel Seismic. Setiap pengujian yang dilakukan di lapangan mengacu pada American Society For Testing and Material (ASTM) dan American Concrete Institute (ACI).

Tabel 1. Standar Pengujian Lapangan

\begin{tabular}{c|c|c}
\hline Jenis Pengujian & Standar & Tujuan \\
\hline Crosshole Sonic Logging & ASTM D-6760-08 & Mengetahui kerusakan pada beton dalam 2 dimensi. \\
\hline Pile Integrity Test & ASTM D-5882-07 & Mengetahui integritas tiang dalam kedalaman total. \\
\hline Parallel Seismic & ACI 228.2R & Mengetahui kedalaman tiang. \\
\hline
\end{tabular}

\section{Metode pengolahan hasil uji}

Dalam pengolahan hasil uji metode Crosshole Sonic Logging, Crosshole Tomography, Pile Integrity Test, dan Parallel Seismic, menggunakan beberapa program dan tahapan untuk mendapatkan hasil untuk dianalisis lebih lanjut. Metode Crosshole Sonic Logging menggunakan program CSL2. Metode Crosshole Tomography menggunakan program CSL2, GeoTom, dan Slicer Dicer. Metode Pile Integrity Test menggunakan program PIT-W. Metode Parallel Seismic menggunakan program Win Geo.

\section{Metode analisis data}

Setelah melakukan pengolahan hasil uji dengan menggunakan program-program setiap metode, hasilnya akan dianalisis untuk didapatkan integritas tiang dari setiap metode kemudian akan dibandingkan setiap metodenya.

\section{ANALISIS DAN PEMBAHASAN}

\section{Hasil analisis Crosshole Sonic Logging}

Hasil analisis Crosshole Sonic Logging dibagi menjadi 2 tahap yaitu pada kedalaman 1-10 meter dan pada kedalaman 11-19.5 meter. Pada kedalaman 1-10 meter menunjukkan adanya perbedaan penurunan kecepatan gelombang pada tiga uji pasang pipa yang memungkinkan adanya kerusakan kecil pada tiang. Pada kedalaman 11-19.5 meter, terlihat sekitar kedalaman 18 hingga 19.5 meter mengalami penurunan kecepatan gelombang yang drastic, hal ini disebabkan adanya kerusakan yang terjadi pada tiang. 
Studi Integritas Tiang dengan Crosshole Sonic Logging, Crosshole Tomography, Pile Integrity Test, dan Parallel Seismic

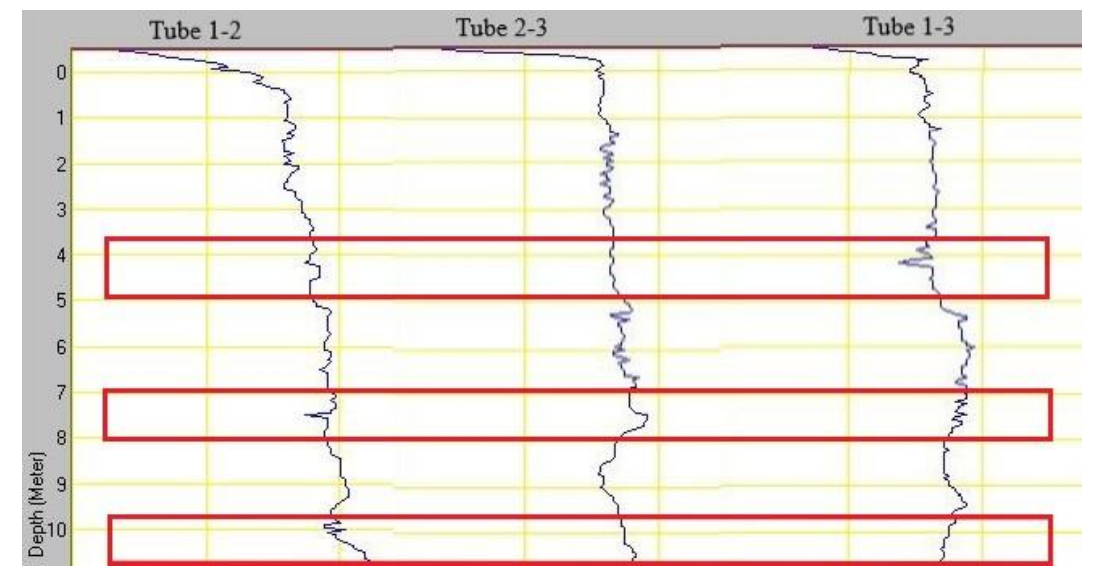

Gambar 1. Hasil analisis pada kedalaman 1-10 meter

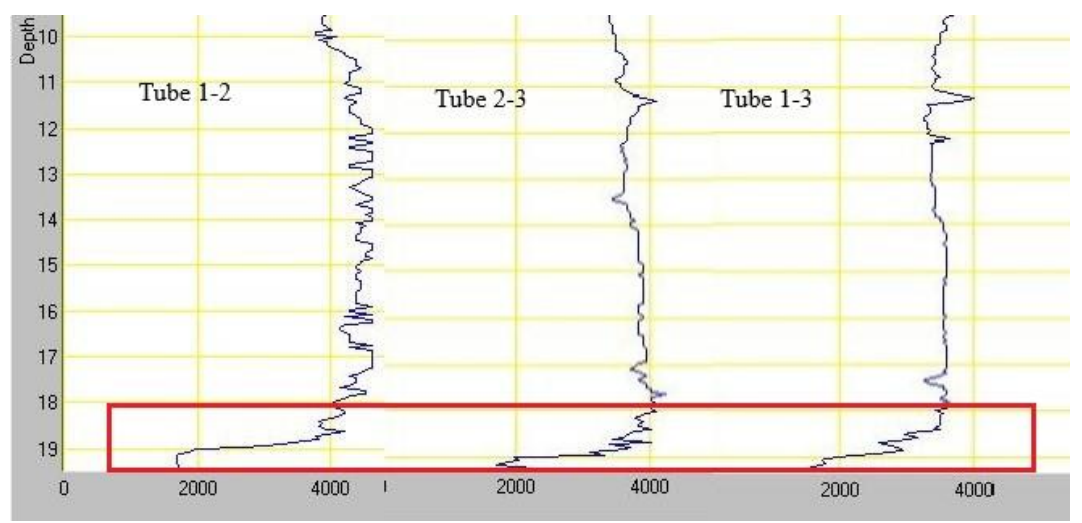

Gambar 2. Hasil analisis pada kedalaman 11-19.5 meter

\section{Hasil analisis Crosshole Tomography}

Hasil analisis Crosshole Tomography ini didapatkan letak kerusakan tiang secara detail dan 3 dimensi. Range kecepetan gelombang dari yang terendah hingga tertinggi ditunjukkan untuk mempermudah mengetahui letak kerusakan pada tiang tersebut.

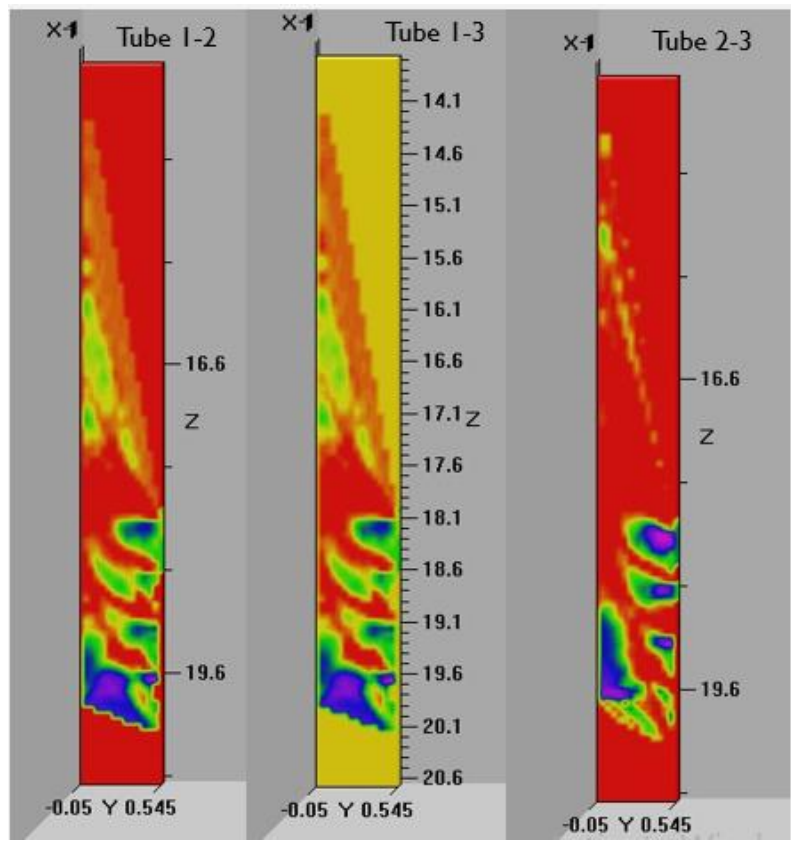

Gambar 3. Hasil Crosshole Tomography yang menunjukkan letak kerusakan 3 dimensi 


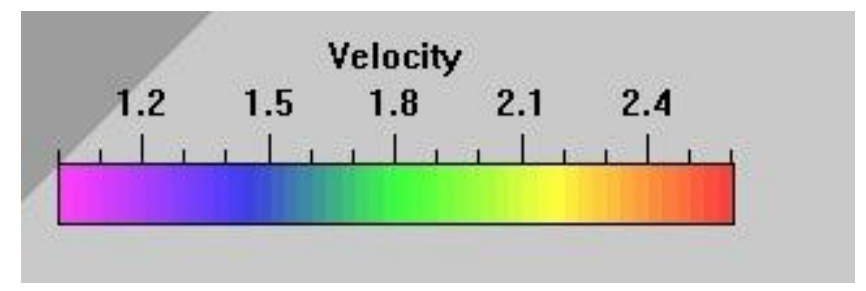

Gambar 4. Range kecepatan gelombang

\section{Hasil analisis Pile Integrity Test}

Berdasarkan hasil uji PIT, akan dianalisa berdasarkan perubahan impedansi (BTA) seperti pada Tabel 2. Pada gambar 5, merupakan lokasi kedalaman yan mengalami perubahan impedansi. Untuk mengetahui perubahan impedansi (BTA), penulis menganalisa berdasarkan acuan ASTM STP 670 yaitu dengan menggunakan perbandingan tinggi perubahan impedansi tersebut.

Tabel 2. Remarks Category

\begin{tabular}{c|c}
\hline BTA $(\%)$ & Category \\
\hline 100 & Undamaged - Pile in good condition \\
\hline $80-99$ & Slight Damaged - Pile has minor problem but still tolerable \\
\hline $60-79$ & Damage - Pile has major problems; further analysis and/or repair needs \\
\hline Below 60 & Broken - Pile to be rejected \\
\hline
\end{tabular}

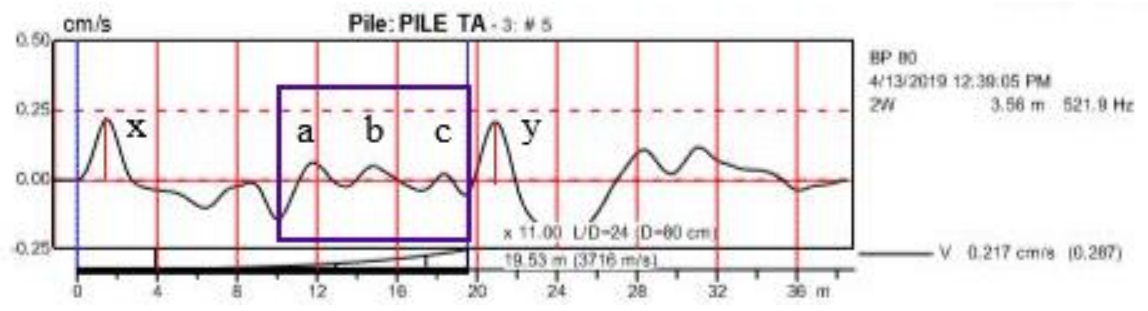

Gambar 5. Analisa PIT terhadap perubahan impedansi (BTA)

Pada bagian A, menunjukkan setelah adanya perbesaran, gelombang kembali normal, dalam bagian ini tidak terjadi perbedaan impedansi (BTA).

Pada bagian B dan C akan dianalisis menggunakan perbandingan tinggi perubahan impedansi (BTA), lalu kemudian dirata-rata setiap kedalaman perubahan impedansi tersebut. Perbandingan tinggi yang penulis gunakan adalah sebagai berikut:

$$
\begin{aligned}
& B=\frac{y-b}{x} X 100 \% \\
& C=\frac{y-c}{x} X 100 \%
\end{aligned}
$$

Hasil analisis perubahan impedansi (BTA) yang didapatkan adalah sebagai berikut:

Tabel 3. Hasil analisis uji PIT terhadap peubahan impedansi (BTA)

\begin{tabular}{c|c|c}
\hline Kedalaman $(\mathrm{m})$ & BTA & Kategori \\
\hline $14-16$ & $71.24 \%$ & Damage \\
\hline $17-19.53$ & $83 \%$ & Slight Damage \\
\hline
\end{tabular}


Studi Integritas Tiang dengan Crosshole Sonic Logging,

\section{Hasil analisis Parallel Seismic}

Hasil analisis Parallel Seismic menunjukkan kedalaman tiang berada pada kedalaman kurang lebih 19 meter. Hal ini dapat dipastikan dengan 2 buah garis kalibrasi dimana garis pertama dan garis kedua saling berhimpit.

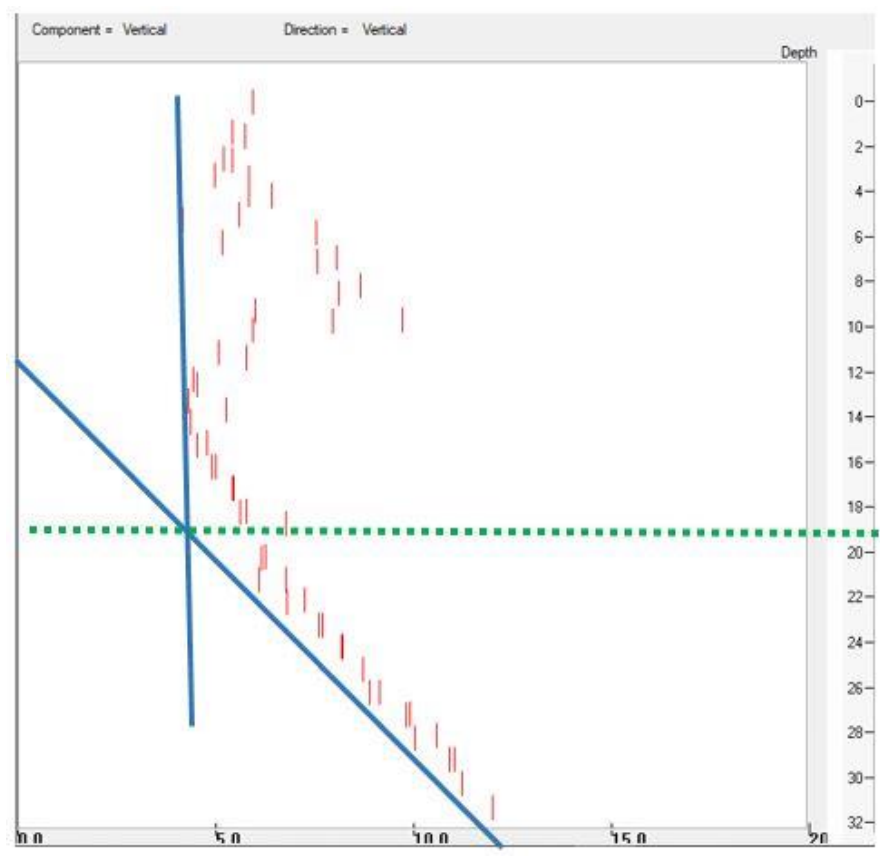

Gambar 6. Hasil analisis Parallel Seismic

\section{KESIMPULAN}

Dari hasil penelitian yang diperoleh, dapat disimpulkan dalam berbagai kategori sebagai berikut:

Tabel 4. Kesimpulan hasil penelitian

\begin{tabular}{c|c|c|c|c}
\hline Kategori & CSL & CT & PIT & PS \\
\hline Kedalaman tiang & - & - & V & V \\
\hline Letak kerusakan & V & V & V & - \\
\hline Detail kerusakan & - & V & - & - \\
\hline Mutu beton & - & - & - & - \\
\hline
\end{tabular}

Keterangan:

$(-)=$ tidak mendeteksi kategori

$(\mathrm{V})=$ dapat mendeteksi kategori

\section{DAFTAR PUSTAKA (DAN PENULISAN PUSTAKA)}

ASTM D-6760-08, "Standard Test Method for Integrity Testing of Concrete Deep Foundation by Ultrasonic Crosshole Testing".

Hardiyatmo, Hary C. 2010. Analisis dan Perancangan Fondasi (Bagian 1). Yogyakarta: Gadjah Mada Univeristy Press. 